\title{
CUIDADOS, ACOLHIMENTO E FLORES: AS MULHERES NA POLÍTICA E DESENVOLVIMENTO LOCAL NO RIO GRANDE DO SUL ${ }^{1}$
}

"Por que nós temos que nos tornar homens para ser política?"

Tânia T. da Silva - Prefeita de Dois Irmãos / RS / BR (Entrevistada)

Ivaldo Ghelen ${ }^{2}$

Olinda Barcellos ${ }^{3}$

Resumo: Neste artigo objetivou-se identificar e analisar trajetórias de empoderamento político de mulheres que exercem funções de representatividade e suas compreensões sobre desenvolvimento local. O recorte analítico é qualitativo e fundamentou-se nos conceitos de empoderamento, chances de vida e capacitações. O universo de pesquisa foram mulheres que assumiram cargos de prefeitas, vice-prefeitas e vereadoras no Rio Grande do Sul, nas eleições de 2012. Também, buscou-se conhecimentos sobre o assunto com informantes qualificados, totalizando trinta e quatro pessoas entrevistadas por meio de um roteiro que abrangeu os seguintes aspectos: a trajetória familiar, educacional e profissional; a trajetória política, a participação em organizações de grupo; atuação na política, o estilo de fazer política; os significados e os compromissos com o desenvolvimento local; e a participação política da mulher. Os resultados demonstraram que a mulher ingressa na política por três vias: pela qualificação profissional, pela participação em movimentos sociais e para ajudar amigos e família; atua na política com especificidades da esfera privada, e sua compreensão de desenvolvimento local não distancia de seu entendimento de bem-estar em casa; não separa sua vivência em família com a atuação na política, dobrando sua carga de compromissos e atividades. Não somam um número que representa uma massa crítica capaz de alterar relação de poder, mas quando estão no poder compreendem o desenvolvimento local como processo de construção de bem estar às pessoas.

Palavras-chave: Empoderamento político; Mulheres políticas; Desenvolvimento local.

\begin{abstract}
The present study aims to identify and analyze trajectories of womens's political empowerment, that have representative roles, and their understanding about the local development. The analysis is qualitative and it is based in empowerment's concepts, life's chances and abilities. The investigation took into account women that were mayors, vice-mayors and councilwomen in the state of Rio Grande do Sul in 2012 elections. Also, the information about the subject came from qualified people, thirty four people was interviewed with a script that included the following aspects: familiar, educational, professional and political ones, participation in goups organizations, performance in politics, the way of working in politics, the meanings and the commitment in relation to local development, and women's participation in politic. The results demonstrated that women joined to politics due to three vias: their professional competence, participation in social activities and to assist their friends and family. They work in politic with specificities from their private lives, and their understanding about local development is similar to their understanding about welfare at home, they do not separate their family living from their political performance, they duplicate their activities and commitments. These women are the rate that represent a critical mass that can not change the power relation, but when they are in the power position they understand the local development as a process of construction of welfare to people.
\end{abstract}

Key words: political empowerment; Political women; Local development.

\section{Introdução}

Este artigo trata sobre mulheres, política e desenvolvimento. Quando alguma mulher, em algum lugar do mundo, pensou que poderia participar de um ambiente fora do lar, onde os homens discutiam e decidiam para o bem comum, teve início um movimento de atração e questionamentos sobre os porquês da sua ausência nesse ambiente, resultando numa conquista pelo direito de participar da política. Quando uma mulher passa a fazer parte da elaboração de políticas de desenvolvimento local, as experiências vivenciadas no lar serão refletidas em suas ações, e o desenvolvimento passará a ter outros significados para além do mero crescimento da produção.

A mulher sujeito do desenvolvimento na esfera de decisão política é o foco deste estudo, sendo que verificar os significados do desenvolvimento para as mulheres políticas requer uma amplitude de análise que vai além do crescimento econômico de uma localidade e do aumento e diversificação da produção. O desen-

\footnotetext{
${ }^{1}$ Artigo desenvolvido a partir da Tese de Doutoramento, defendida em junho de 2015 na UFRGS.

${ }^{2}$ Doutor em Sociologia pela Université de Paris X e professor na UFRGS

${ }^{3}$ Doutora em Desenvolvimento Rural pela UFRGS. Professora da FADISMA e da FAPAS
} 
volvimento relatado passa a ser entendido enquanto melhoria das condições de vida das pessoas no meio onde vive.

A participação e a liderança das mulheres políticas no desenvolvimento local contribuem para compreensão do significado desse desenvolvimento. Essa análise fundamenta-se em Amartya Sen (2010), que defende a participação e a liderança política, econômica e social das mulheres como aspecto crucial do 'Desenvolvimento como liberdade'.

Sendo assim, examinar o papel das mulheres na esfera política é importante para compreender as características de novos atores políticos, com outras especificidades e comportamentos em relação à prática política até então estabelecida, possibilitando, assim, tornar o desenvolvimento local mais solidário e com mais equidade nessa representatividade política.

No Rio Grande do Sul, nem 10\% das prefeituras são ocupadas por mulheres, elas representam participação irrisória na imensidão da representação masculina. Os dados não se alteram no restante dos estados brasileiros, as mulheres estão sub-representadas politicamente. O machismo de homens e mulheres ainda é muito forte na cultura brasileira, onde cada sexo/ gênero tem um papel na sociedade e, na esfera política, o domínio é dos homens sob o disfarce de um discurso que as mulheres não gostam de política.

O ambiente político, de cargos elegíveis de poder de decisão, é masculino, refletindo uma desigualdade de gênero característica da cultura patriarcal e nas relações sociais da história brasileira. No site do TSE ${ }^{4}$, na lista onde constam os dados dos resultados de uma eleição, o cargo prefeito aparece em todos os municípios, independente se é homem ou mulher que está ocupando; ou seja, não consta a palavra prefeita quando mulher, e sim prefeito. Igual situação relativa à palavra eleito, independente de ser homem ou mulher ocupante do cargo. Isso é um exemplo da masculinidade política, onde ainda não se exercita uma linguagem de gênero.

Portanto, para o desenvolvimento deste artigo, partiu-se da ideia de que, independente de suas trajetórias de participação política, a atuação das mulheres e o envolvimento no desenvolvimento local refletem as experiências vivenciadas na esfera privada, lugar de que tem o domínio. Dessa forma, este trabalho se propõe a identificar e analisar trajetórias de empoderamento político de mulheres que exercem funções de representatividade no Rio Grande do Sul e seu entendimento na perspectiva do desenvolvimento local.

A abordagem teórica utilizada na produção do conhecimento foi a hipotética-dedutiva, e o procedimento utilizado para coletar e analisar os dados é o qualitativo. A composição metodológica deste estudo está dividida em duas dimensões: teórica e empírica. A análise teve início a partir da observação sobre a representatividade das mulheres que exercem funções de política eletiva no estado do Rio Grande do Sul. A partir das observações sobre a representatividade feminina na política eletiva elegeu-se o grupo de participantes.

Optou-se pelas eleitas para o cargo de prefeitas, vice-prefeitas e vereadoras. Todas foram eleitas em resultado da legitimação no Rio Grande do Sul, nas eleições de 2012. As participantes do estudo foram quinze mulheres entrevistadas, sendo seis prefeitas, duas vices-prefeitas e sete vereadoras, eleitas no pleito de 2012, no RS e atuantes politicamente. Dezenove pessoas, entre homens e mulheres, participaram desta pesquisa como casos ilustrativos, por conhecerem o assunto, totalizando trinta e quatro pessoas. 
Quadro 01: Relação das mulheres entrevistadas eleitas em 2012

\begin{tabular}{|c|c|c|c|c|c|}
\hline $\begin{array}{l}\text { No da entrev- } \\
\text { ista }\end{array}$ & Cargo & Cidade & $\begin{array}{l}\text { Partido Político / Coli- } \\
\text { gações }\end{array}$ & $\begin{array}{l}\text { Atividade profissional/Área de } \\
\text { formação }\end{array}$ & $\begin{array}{l}\text { Primeiro cargo } \\
\text { eletivo? }\end{array}$ \\
\hline 01 & Prefeita & São João do Polêsine & PMDB (PMDB / PSDB) & $\begin{array}{l}\text { Professora Estadual - Letras/ } \\
\text { Português }\end{array}$ & Não \\
\hline 02 & Prefeita & Ivorá & $\begin{array}{l}\text { PMDB (PT / PTB / } \\
\text { PMDB) }\end{array}$ & $\begin{array}{l}\text { Professora Estadual - Letras Por- } \\
\text { tuguês e Inglês; Administração }\end{array}$ & Não \\
\hline 03 & Prefeita & Vera Cruz & PP & $\begin{array}{l}\text { Professora Municipal - Pedagogia } \\
\text { e Pós em Educação Infantil }\end{array}$ & Não \\
\hline 04 & Prefeita & Júlio de Castilhos & PSDB & Professora Estadual - Magistério & Não \\
\hline 05 & Prefeita & Dois Irmãos & $\begin{array}{l}\text { PMDB (PP / PTB / } \\
\text { PMDB) }\end{array}$ & Enfermeira- Enfermagem & Não \\
\hline 06 & Prefeita & Nova Santa Rita & $\mathrm{PT}$ & Professora Estadual - Magistério & Não \\
\hline 07 & Vice-prefeita & Cachoeira do Sul & $\mathrm{PT}$ & Ciências Sociais & Não \\
\hline 08 & Vice-prefeita & Dona Francisca & $\mathrm{PP}(\mathrm{PDT} / \mathrm{PT})$ & $\begin{array}{l}\text { Funcionária do Posto de Saúde - } \\
\text { Técnica em Administração }\end{array}$ & Não \\
\hline 09 & Vereadora & Vera Cruz & $\mathrm{PT}(\mathrm{PT} / \mathrm{PR})$ & Agente de Saúde - Ensino Médio & Não \\
\hline 10 & Vereadora & Faxinal do Soturno & $\mathrm{PP}(\mathrm{PP} / \mathrm{PSDB})$ & Professora Estadual - Magistério & Não \\
\hline 11 & Vereadora & São João do Polêsine & PMDB (PMDB / PSDB) & $\begin{array}{l}\text { Funcionária do STR - Gestão } \\
\text { Pública; Pedagogia; Especialização } \\
\text { em Gênero e Raça (UFSM) }\end{array}$ & Sim \\
\hline 12 & Vereadora & Santa Maria & $\mathrm{PP}$ & $\begin{array}{l}\text { Professora Estadual - Pedagogia; } \\
\text { Direito }\end{array}$ & Não \\
\hline 13 & Vereadora & Dois Irmãos & PP (PP / PTB / PMDB) & $\begin{array}{l}\text { Professora - Educação Física } \\
\text { e Especialização em Mídias na } \\
\text { Educação }\end{array}$ & Sim \\
\hline 14 & Vereadora & Santa Cruz do Sul & PTB (PTB / PT do B) & $\begin{array}{l}\text { Funcionária de cargo de confiança } \\
\text { por } 16 \text { anos na Prefeitura }\end{array}$ & Sim \\
\hline 15 & Vereadora & São Pedro do Sul & PTB (PP / PTB / DEM) & Professora Estadual -Magistério & Sim \\
\hline
\end{tabular}

Fonte: Elaboração própria a partir dos dados coletados nas entrevistas com as políticas que fazem parte do núcleo central da pesquisa (Prefeitas, Vices e Vereadoras) e no site do Tribunal Superior Eleitoral - Eleições. Dados coletados em 2014.

Quadro 02: Relação de informantes qualificados no Brasil

\begin{tabular}{|c|l|l|c|l|}
\hline $\begin{array}{c}\text { No da en- } \\
\text { trevista }\end{array}$ & \multicolumn{1}{|c|}{ Cargo } & \multicolumn{1}{|c|}{ Cidade } & $\begin{array}{c}\text { Partido Político / } \\
\text { Coligação }\end{array}$ & \multicolumn{1}{|c|}{ Atividade profissional/Área de formação } \\
\hline 16 & Senadora & Brasília/Brasil & PP & Jornalista - Comunicação Social \\
\hline 17 & Deputada Estadual & Porto Alegre/RS & PT & $\begin{array}{l}\text { Professora Municipal - Magistério; acadêmica de } \\
\text { Ciências Sociais/Unisinos }\end{array}$ \\
\hline 18 & Deputada Estadual & Porto Alegre/RS & PSDB & Professora - Magistério \\
\hline 19 & Deputado Estadual & Porto Alegre/RS & PSB & $\begin{array}{l}\text { Presidente do Sindicato dos Trabalhadores } \\
\text { Rurais e da FETAG }\end{array}$ \\
\hline 20 & $\begin{array}{l}\text { Presidente da Associação de Mul- } \\
\text { heres Produtoras Rurais }\end{array}$ & $\begin{array}{l}\text { Comunidade de } \\
\text { Riacho dos Negros } \\
- \text { Palmeirais - Piauí }\end{array}$ & - & Costureira - 5árie \\
\hline 21 & $\begin{array}{l}\text { Presidente da Associação dos } \\
\text { Pequenos Produtores Rurais de } \\
\text { Penicilina }\end{array}$ & $\begin{array}{l}\text { C o m u n i d a d e } \\
\text { de Penicilina - } \\
\text { Palmeirais - Piauí }\end{array}$ & Trabalha na Roça - 3a série do ensino funda- \\
\hline
\end{tabular}




\begin{tabular}{|c|c|c|c|c|}
\hline $\begin{array}{l}N^{\circ} \text { da en- } \\
\text { trevista }\end{array}$ & Cargo & Cidade & $\begin{array}{c}\text { Partido Político / } \\
\text { Coligação }\end{array}$ & Atividade profissional/Área de formação \\
\hline 22 & $\begin{array}{l}\text { Presidente da Associação dos } \\
\text { Pequenos Produtores Rurais da } \\
\text { Comunidade de Buritizinho }\end{array}$ & $\begin{array}{l}\text { Comunidade de } \\
\text { Buritizinho - } \\
\text { Palmeirais - Piauí }\end{array}$ & PSB & $\begin{array}{l}\text { Trabalha na Roça - } 5^{\text {a }} \text { série do ensino funda- } \\
\text { mental }\end{array}$ \\
\hline 23 & $\begin{array}{l}\text { Presidente do Sindicato dos Tra- } \\
\text { balhadores Rurais de Cachoeira do } \\
\text { Sul e Novo Cabrais }\end{array}$ & Cachoeira do Sul & - & $\begin{array}{l}\text { Agricultora - Acadêmica no PLAGEDER - Cur- } \\
\text { so Superior de Desenvolvimento Rural }\end{array}$ \\
\hline 24 & Vereadora & Tejuçuoca / Ceará & PSB & Professora Municipal - Português \\
\hline 25 & Vereadora & Tejuçuoca / Ceará & PDT & Curso superior incompleto \\
\hline 26 & $\begin{array}{l}\text { Secretária da Gerência da Mulher - } \\
\text { Secretaria de Assistência Social do } \\
\text { Município }\end{array}$ & Palmeirais - Piauí & $\begin{array}{l}\text { Políticas Públicas } \\
\text { para Mulheres }\end{array}$ & Professora Municipal - Pedagogia \\
\hline 27 & $\begin{array}{l}\text { Coordenadora Executiva da Orga- } \\
\text { nização Themis - Gênero, Justiça e } \\
\text { Direitos Humanos }\end{array}$ & Porto Alegre/RS & $\begin{array}{l}\text { Empoderamento } \\
\text { das mulheres }\end{array}$ & Professora Dra. e Advogada - Direito \\
\hline
\end{tabular}

Fonte: Elaboração própria a partir dos dados coletados nas entrevistas com os informantes qualificados e no site do Tribunal Superior Eleitoral Eleições. Dados coletados em 2014.

Quadro 03: Relação de informantes qualificados em Cuba

\begin{tabular}{|c|l|l|l|l|}
\hline $\begin{array}{c}\text { No da infor- } \\
\text { mação }\end{array}$ & \multicolumn{1}{|c|}{ Cargo } & \multicolumn{1}{|c|}{ Tema } & \multicolumn{1}{c|}{$\begin{array}{c}\text { Atividade } \\
\text { profissional }\end{array}$} \\
\hline 28 & Professor & Situaçãão Política de Cuba & Universidade de Havana & Prof. Dr. \\
\hline 29 & Professora & Situação da Mulher Cubana & Universidade de Havana & Prof. Dra. \\
\hline 30 & $\begin{array}{l}\text { Funcionária de Relações } \\
\text { Internacionais da FMC }\end{array}$ & $\begin{array}{l}\text { Participação Feminina no Poder } \\
\text { Popular }\end{array}$ & Federação das Mulheres Cubana & Licenciada \\
\hline 31 & Professora & $\begin{array}{l}\text { Empoderamento das mulheres } \\
\text { cubanas }\end{array}$ & Universidade de Havana & Prof. Dra. \\
\hline 32 & $\begin{array}{l}\text { Funcionária do Ministério } \\
\text { da Agricultura }\end{array}$ & Programa IGECSA & Ministério da Agricultura & $\begin{array}{l}\text { Funcionária } \\
\text { Dra. }\end{array}$ \\
\hline 33 & $\begin{array}{l}\text { Deputada - Delegada de } \\
\text { Base Presidente do Conselho } \\
\text { Popular Rampa }\end{array}$ & Mulher na Política Cubana & Assembléia Nacional & $\begin{array}{l}\text { Secretária } \\
\text { Taquimeca } \\
\text { Bilingue }\end{array}$ \\
\hline & Professora & Situação da mulher cubana & Universidade de Havana & $\begin{array}{l}\text { Prof. Dra. } \\
\text { Presidente da } \\
\text { Cátedra de La } \\
\text { Mujer }\end{array}$ \\
\hline
\end{tabular}

Fonte: Elaboração própria a partir dos dados coletados nas entrevistas com os informantes qualificados e no site do Tribunal Superior Eleitoral Eleições. Dados coletados em 2014.

O artigo está estruturado em três tópicos a partir desta introdução. O primeiro item explica as mulheres na política do RS sob três óticas: participação, legitimidade e representatividade. Na sequência, o tema é preconceito e participação feminina na política representativa, e no terceiro item, a proposta é verificar como as mulheres compreendem o desenvolvimento local, quando em cargo eletivo. Finalmente, as considerações finais sobre o estudo desenvolvido.

\section{Participação, legitimidade e representatividade de mulheres na política no RS}

Esta parte analisa a trajetória de empoderamento, através do espaço feminino da política representativa e a política como espaço de poder para as mulheres.

\subsection{O espaço feminino na política representativa}

As conquistas atuais, de um modo geral, e as políticas em especial, refletem muito as lutas incansáveis do movimento feminista. Educação igual para meninas e meninos, mulheres com direito a bens da famí- 
lia, direito de votar e ser voltada, são exemplos de conquistas de uma longa luta de reivindicações promovidas pelas feministas. As mudanças estão acontecendo, no entanto, é um caminho longo que exige persistência.

A partir das primeiras vozes levantadas em prol da defesa dos direitos da mulher, inicia-se um processo de empoderamento. Inicia-se um processo de busca de poder, até então de posse de somente uma parte da população, é a mudança em perspectiva. O empoderamento econômico das mulheres é a chave do desenvolvimento do país. "El empoderamiento económico se define como el hecho de tener acceso y control de los medios necesarios para poder vivir en condiciones sostenibles a largo plazo, y de recibir los beneficios de dicho acceso y contro. (CARR, 2000, p. 8).

John Stuart Mill, quando escreveu The subjection of Women, em 1869, afirmou que o conhecimento que os homens podem adquirir sobre as mulheres é imperfeito e superficial, e que ainda iria passar algum tempo para que as próprias mulheres pudessem, elas mesmas, defender suas ideias. A preocupação do pensador era com a liberdade, no entanto, a discussão sobre a igualdade entre homens e mulheres esteve presente na obra do filósofo liberal, ou seja: “Ao longo de toda a evolução da história humana, a condição das mulheres tem-se vindo a aproximar da igualdade com os homens" (MILL, 2006, p.71).

Mill (2006) se pronunciou oficialmente em defesa do voto feminino. Seu discurso pela igualdade do homem e da mulher na família e na sociedade o transformou em ativista do feminismo. No entanto, a sociedade resistia à argumentação de Stuart Mill e, no final do século XIX, ainda se acreditava que a mulher representasse uma subespécie cujo único destino era a procriação (SAFFIOTI, 2013).

O movimento feminista transformou a condição das mulheres em vários locais do mundo. Luta incansável por igualdade e liberdade resultou em conquistas femininas indiscutíveis, com ações contra a desigualdade e discriminação que modificaram o comportamento das mulheres. Esse movimento teve início ainda no século XIV, através do discurso da poeta francesa Christine de Pisan, defendendo uma educação igual para meninas e meninos (ALVES e PITANGUY, 2007).

Olympe de Gouges, escritora francesa que publica Os Direitos da Mulher e da Cidadã, foi guilhotinada em três de novembro de 1793. "A sentença que a condenou acusava-a de ter querido ser um homem de Estado e ter esquecido as virtudes próprias a seu sexo" (ALVES e PITANGUY, 2007, p. 34). Após a Revolução Francesa, mesmo que escassamente, houve certo alargamento das liberdades humanas, mas não para todas as pessoas, nem para os dois sexos de forma igual. "O alargamento das liberdades humanas foi processo que atingiu escassamente a mulher, independentemente da classe social a que pertence" (SAFFIOTI, 2013, 161). Fez-se silêncio por três décadas. Era um indício de que essa luta seria longa.

No início do século XIX, várias vozes se levantaram em prol de mais direitos para as mulheres, sejam eles de ordem econômica, social, sexual ou política. A política é apenas uma parte desse processo de empoderamento, e, como já referenciado, tem se mostrado a parte mais sensível da trajetória de luta por direitos de cidadania. O século XX foi marcado pela luta crescente das mulheres pelo reconhecimento de seus direitos políticos. Em 1933, Carlota Pereira de Queiroz, médica, é eleita a primeira Deputada Federal do Brasil pelo estado de São Paulo. No mesmo ano, Almerinda Gama, trabalhadora negra, é eleita Deputada Classista para a Assembleia Nacional Constituinte de 1934. Nas eleições estaduais de 1934 nove deputadas estaduais foram eleitas, mas nenhuma no RS.

As primeiras mulheres que assumiram cargos de representação política no Brasil são instruídas e de origem econômica abastada, como Alzira Soriano, a primeira prefeita, era filha de fazendeiro e de pele branca. Maria do Céu Fernandes de Araújo, primeira deputada estadual, era filha do coronel e tradicional político Vivaldo Pereira, e irmã do ex-governador José Cortez Pereira de Araújo. Carlota Pereira de Queiroz, primeira 
deputada federal, era médica (TILLY, 1994; AVELAR, 2001).

A origem social, o nome de família rica e a presença de homens políticos na família são elementos que explicam as conquistas políticas dessas mulheres, principalmente quando se refere à instrução. Leram, aprenderam, tiveram condições de formular críticas, ou seja, já se encontravam em processo de empoderamento. É normal que as primeiras mulheres na política tenham sido pessoas que avançaram mais no processo de empoderamento, no entanto, essas mulheres tiveram uma grande responsabilidade, pois é a partir delas que as demais se vêem no caminho político, elas servem como exemplo.

Quando ocorre pela primeira vez um evento, como é o caso da eleição da primeira prefeita negra do RS, em 2012, o impacto é forte, visto ser uma novidade, com muita publicidade e curiosidade sobre quem é a pessoa, como chegou lá, vários questionamentos sobre suas capacidades, ou a possibilidade de ser apenas voto de protesto, situações essas que enfrentou a prefeita da cidade de Dois Irmãos, de colonização alemã.

Pode se tratar de um evento que se traduz em orgulho, mas também muito perigoso, por se tratar de uma posição de símbolo; ou seja, essa mulher é a representante de outras mulheres no geral, nesse caso específico, das mulheres negras 5 . Para essa mulher símbolo o erro quase não é permitido.

O movimento feminista é assim, recheado de eventos ocorridos pela primeira vez, desde o século XIV. Pelo próprio sentido do feminismo, considera-se o movimento exatamente como um movimento, não para nunca, e se alimenta por cada nova ideia nele inserida. Então, uma sociedade democrática e cidadã passa por desconstruir estereótipos para avançar em direção à igualdade de direitos e à equidade de gênero (PRÁ; EPPING, 2012).

No entanto, tem autor que defende já se estar vivendo a fase do pós-feminismo. Se o movimento feminista reflete um movimento pela igualdade entre mulheres e homens, o movimento pós-feminista se volta para a própria mulher ${ }^{6}$. Touraine (2011) relata que as mulheres do pós-feminismo não querem construir uma sociedade de mulheres e sim criar, a partir delas próprias, um novo modelo de cultura, ou melhor, uma sociedade de homens e mulheres. O feminismo foi importante no sentido que serviu de orientação e ação para mudar as leis, a política e a opinião pública; já no pós-feminismo, as mulheres querem transformar e reconstruir uma relação com elas mesmas; uma busca incessante pelo convívio sem hierarquias entre homens e mulheres.

As mulheres do pós-feminismo, principalmente as francesas do estudo de Touraine (2011), têm um comportamento indiferente em relação à ação política; elas reconhecem que o espaço que o sistema político destina a elas é reduzido, no entanto não acreditam mais na ação política no mundo em que vivem. O pósfeminismo permitiu a construção de uma sociedade de mulheres, onde os homens vivem em uma posição de reciprocidade nas relações.

\subsection{A política como espaço de poder para mulheres}

O espaço do poder político tem sido ocupado no país pela primeira vez por mulheres de 1928 até 2011, considerando-se as desbravadoras que ocuparam cargo de prefeita até presidenta. É quase um século das primeiras ocupações de cargos políticos por mulheres. Percebe-se que não basta apenas ter o bilhete de ingresso ${ }^{7}$, é preciso manter um grau de confiança elevado que possibilite as escolhas em um ambiente reconhecidamente incerto como o da política partidária e representativa.

${ }^{5}$ Dahlerup (1986) cita um trabalho realizado por Rosabeth Moss Kanter (1977) sobre o conceito de símbolo e enumera alguns dilemas e contradições para o indivíduos que estão em posição de símbolos.

6 "O pós-feminismo não é um movimento social, mas um movimento de reconstrução cultural pela superação dos conflitos e polarizações que emprestaram sua força principal ao modelo europeu de modernização” (TOURAINE, 2011, p. 117).

${ }^{7}$ Parte do conceito de chance de vida do sociólogo liberal Ralf Dahrendorf. 
Ainda que a cada ano as primeiras se multipliquem, são ainda raras na paisagem do poder as figuras femininas. Ainda hoje, muitas mulheres chegam a espaços institucionais de exercício do poder carregando consigo um desejo secreto de que os 'outros' não percebam que são mulheres. 'Duronas' ou 'histéricas', 'exibidas' ou 'mulherzinhas', 'peruas ou machonas' são adjetivos utilizados quando se trata de caracterizar as mulheres que chegaram ao poder político ${ }^{8}$.

Considerando as cinco eleições pós a entrada em vigor da lei de cotas para as mulheres no legislativo, entre 1996 e 2012, é possível verificar que o empoderamento político das mulheres, como instrumento de transformação, é um processo longo, que em muitos casos sua efetivação não irá ocorrer somente pela conquista dos direitos de cidadania. As capacidades das mulheres têm sido ampliadas, elas têm conquistado prerrogativas, ou seja, as mulheres estão sendo empoderadas com aumento de sua capacidade de se tornar agente. O Estado tem sido um agente externo promotor do empoderamento, a exemplo da publicação da lei de cotas para o legislativo. No entanto, o caminho à igualdade democrática de gênero é longo.

No caso do Executivo municipal, que não faz parte da lei de cotas, verifica-se que na evolução das cinco eleições brasileiras entre 1996 e 2012, houve aumento de mulheres eleitas prefeitas em torno de 3\% de um período eleitoral a outro. É um número irrisório, considerando que as mulheres são mais da metade da população brasileira. No entanto, se considerarmos a história da mulher e do Brasil, do poder local dominado por 'coronéis', mesmo que esse nome seja válido até hoje para vários tipos de empoderamentos masculinos de poder, compreende-se que o caminho que as mulheres percorrem em direção ao trabalho político é em passos lentos e requer paciência e perseverança. Percebe-se que conquistar prerrogativas e aumentar capacitações é um processo lento.

Em 1996, o RS com 467 municípios, elegeu somente doze prefeitas, nem 3\% do total. Nas eleições de 2000, que inaugura o novo século, foram eleitas apenas nove prefeitas, sendo que o Paraná foi único estado que apresenta os melhores resultados nessas eleições, pois em 1996 elegeu oito prefeitas e em 2000, dezoito mulheres são eleitas prefeitas. Santa Catarina elege cinco prefeitas nas duas eleições, de 1996 e 2000. A partir das eleições de 2004, o RS surpreende elegendo quase o dobro de mulheres para prefeituras, dezessete no total em 2004, vinte e duas em 2008 e trinta e cinco em 2012, análise central desse estudo.

Mas será que o número absoluto faz a diferença? Drude Dahlerup (1986) trabalhando com o conceito de massa crítica, situação de um grupo minoritário com condições de realizar mudanças na estrutura de poder imposta e também na própria condição do grupo, analisa a questão da mulher quando esta pode vir a estar numa situação de símbolo, com todos os dilemas e contradições dessa condição. Pois, nem sempre uma quantidade maior de mulheres irá constituir uma massa crítica.

As eleições para o poder Legislativo sofreram mudanças com a publicação da lei de cotas, a partir de 1996. A pesquisa de Jussara Prá (2005) mostrou que houve um aumento de mais de 66\% entre 1992 e 1996 nas eleições para vereadoras em todo o Brasil, de 3.952 vereadoras eleitas em 1992 para 6.598 em 1996. No entanto, nas eleições de 2000 não houve o mesmo impulso, aumento somente em torno de 7\%. Em 2004 e 2008 não houve acréscimo algum no número de vereadoras eleitas.

Um olhar matemático da situação, sem considerar as trajetórias, os motivos, as condições de entrada e concorrência dentro dos partidos políticos e a aceitação da população para votar em uma mulher para vere-

\footnotetext{
${ }^{8}$ A participação das mulheres na política brasileira ocorreu de forma diferenciada, desde os movimentos feministas, a conquista do sufrágio e a participação no pleito eleitoral. Marcelo S. Rindeti (1990) escreveu sobre a participação política das mulheres no período entre 1960 e 70; demonstrou que foi diferenciada a participação, quer apoiando o movimento de entrada de militares em 1964, quer para combatê-lo e apresentou um dado entre 15 a 20\% de mulheres no total de pessoas que participavam dos grupos armados.
} 
adora, verifica-se que a ação afirmativa de cotas na política foi responsável por uma elevação acumulada do período, 1996 e 2012, em torno de 12\%. No entanto, se computar os resultados das eleições de 1992 nesse cálculo, constata-se que o acumulado do período eleva para $83 \%$. Se apenas for divido o número total de vereadoras eleitas no Brasil, em 2012, pelo total de municípios no mesmo ano, percebe-se que foi eleita em torno de uma vereadora por município.

A composição da política representativa das mulheres no estado do Rio Grande do Sul teve início com uma vereadora e uma prefeita, as quais exerceram o cargo político apenas depois de se empoderarem profissionalmente. Como médica e professora, tinham facilidade no contato com a população, permitindo uma aproximação com credibilidade que resultou em um voto de confiança para que atuassem também na esfera política (DICIONÁRIO MULHERES DO BRASIL, 2000).

Considerando o período pós-legislação de cotas na política, o aumento de mulheres eleitas para prefeituras do Rio Grande do Sul, entre 1996-2012, não elevou mais do que 2,6\%, inclusive apresentando uma queda nesse período. Se em 1996 as mulheres não somavam nem 3\% das prefeituras do RS, em 2000, o resultado foi pior, não alcançou nem 2\%. Em 2012, 7\% das prefeituras gaúchas são chefiadas por mulheres, um aumento pífio levando em conta que as mulheres são mais da metade da população do estado. Essa percentagem traduz a baixa participação das mulheres na política, tanto em nível nacional como no RS, pois apenas em 35 municípios, num total de 497 foram eleitas mulheres para prefeitas, deixando de analisar as reeleitas, como é o caso da prefeita de Vera Cruz.

As prefeitas representam em torno de $13,4 \%$ da representatividade política municipal em todo o país, nas eleições de 2012. No estado do RS, lócus deste estudo, a situação de subrepresentatividade feminina em cargos de poder político, principalmente para prefeitas eleitas em 2012, segue a composição encontrada no restante do país, com agravante de ser ainda menor o percentual de representação feminina.

Para o cargo de vereadora, o percentual de candidatas seguiu conforme a lei de cotas, $33 \%$ do total de pessoas que irão concorrer à vereança são mulheres. No entanto, apenas $14 \%$ das mulheres candidatas são eleitas. Um resultado desolador, se for considerado que o exercício da vereança é a porta de entrada para a política, é o cargo que representa o aprendizado, o trabalho com a comunidade na esfera política, a determinação e o início de um caminho de abdicação e comprometimento com a vida política. Uma preparação para a atuação em cargo de mais alto grau da política, importante ao aprendizado político, visto que a mulher está ingressando num ambiente dominado por homens, com uma estrutura que reflete a 'cara' do homem.

A participação política e o empoderamento das mulheres não são de interesse apenas das mulheres, mas sim de homens e mulheres, pois significa uma parte fundamental do trabalho pela construção de uma democracia com mais paridade, capaz de promover os direitos humanos e a equidade.

\section{Preconceito e participação feminina na política representativa}

As mulheres políticas do RS seguiram quais trajetórias de empoderamento? Como elas atuam? Quais barreiras enfrentam? Essas questões analisadas a seguir tem como base as repostas das entrevistas.

\subsection{A participação como impulsor da igualdade de gênero}

Nesta pesquisa, do total de pessoas entrevistadas (quinze participantes da pesquisa e dezenove casos ilustrativos), dezenove (19) trabalharam, ou ainda trabalham como professora, ou seja, 56\% das entrevistadas têm origem na educação. Quatro (04) são oriundas da área da saúde, e onze (11) têm origem diversa como trabalho na área rural, funcionárias públicas, estudante e costureira. 
A professora Eva A. Blay (1979) pesquisou mulheres prefeitas na década de 1970, a fim de esclarecer qual é o real espaço que é ocupado pela mulher na política brasileira, ainda como e por que o processo político brasileiro absorve a mulher na política local. Os resultados da pesquisa realizada nos anos de 1970 não diferem em muito dos resultados da pesquisa realizada com as políticas eleitas em 2012.

Quanto a caracterização socioeconômica das prefeitas, na principal ocupação das que exerciam atividade econômica predominavam as professoras. A mesma ocupação profissional das entrevistadas neste estudo. Trabalhar como professora é atuar em um cargo de reconhecimento público, com prestígio, gratidão e confiança por parte da população. Outro fato coincidente entre as duas pesquisas é a presença de aposentadas. A maioria das políticas de profissão professora já estava em situação laboral de aposentadorias. Para tanto, uma vereadora informou que somente ingressou na política depois da aposentadoria da escola.

Para as prefeitas, vices e vereadoras entrevistadas a família representa um porto seguro, um lugar especial onde elas têm muito orgulho em relatar sobre suas origens. Falam muito e com muito orgulho sobre sua origem familiar pobre e as dificuldades que passaram em casa, junto com pais e irmãos. Entre as quinze entrevistadas, doze tem filhos e dez são casadas.

A maioria tem políticos na família, geralmente homens: pais, irmãos, tio, avô e marido. Algumas relataram que os maridos eram apaixonados pela política, mas não concorriam, então se 'realizavam' nelas, eram seus projetistas. Algumas mulheres se assustaram quando tiveram que ocupar um cargo que, até então, era do marido, pois trabalhavam como mediadoras e agora se tornaram o sujeito político do casal, ou seja, passou de mediadora para agente.

A trajetória de empoderamento político contou com participações em movimentos sociais, principalmente os relacionados com emancipações de municípios e os relacionados com educação, área de formação da maioria das políticas. A filiação partidária aconteceu pouco antes da candidatura para algum cargo político. O convite de amigos ou conhecidos partidários foi motivado por reconhecimento da qualidade profissional, destaque e desenvoltura; muitas vezes sem acreditar, somente com a intenção e necessidade de fechar os números, no legislativo em razão das cotas de gênero.

As mulheres políticas entendem que, independentemente da motivação, a qualificação profissional foi fator imperativo para atuar na política. Verifica-se presente a teoria das capacitações de Amartya Sen (2000), com a defesa de que quanto mais capacitações, mais desenvolvimento humano, maior condições de viver em liberdade.

Apesar das mulheres terem o prévio conhecimento sobre quando estão sendo convidadas na condição de 'laranjas', quando estão sendo convidadas para 'ajudar o partido', algumas candidaturas causaram surpresas aos homens do partido, pois se candidataram e ganharam, sendo que, segundo as entrevistas, não era esse o plano dos homens do partido político. Relataram que foram mais que um número, são vereadoras e são muito ativas.

Essa situação de surpresa por parte dos homens dos partidos foi relatada pelo deputado estadual entrevistado, o qual disse que tem muitas mulheres que entram como laranja apenas para preencher a chapa, mas que "deu azar, as mulheres se elegeram, o partido deve estar olhando e dizendo "mas por que nós botamos essa mulher aqui e tiramos a vaga do fulano, do beltrano?". Criticou essa situação, sugerindo que a Justiça eleitoral deveria investigar para ver se não é laranja, principalmente para vereador. Defende que a justiça eleitoral precisa efetivar a nominata.

As mulheres atuam na política de forma diferente da dos homens? As entrevistadas relataram que atuam de forma diferente do homem. Disseram que trabalham de forma mais solidária, são mais sensíveis aos 
problemas da comunidade, ouvem mais as pessoas, conversam mais, acreditam que tem um jeito feminino, mais humano de trabalhar em relação ao homem. Disseram que usam a psicologia da mulher, que gostam de privilegiar o lado social, mais humano das relações. Informaram que o homem separa muito o trabalho político do familiar, mas que a mulher não consegue fazer isso, pois para elas a política e a família fazem parte de um todo. Inclusive uma prefeita disse que cuida das pessoas do município como se fossem seus filhos, como também a limpeza da cidade como se fosse sua casa. O local das mulheres é a casa e o trabalho, como se os dois fossem apenas um.

As mulheres não se consideram tão partidárias. Para elas, os homens são mais partidários, mais adversários politicamente, e elas são mais solidárias com pessoas de outros partidos. Gostam e preferem trabalhar em conjunto com políticos de outros partidos. Não gostam da solidão partidária. Que optam por trabalharem colaborando com pessoas de outros partidos a ficarem sozinhas em seu grupo partidário. Uma professora/ diretora que ingressou à política após se aposentar, relatou que sua maior dificuldade no exercício da vereança é viver o partidarismo, a solidão que a filiação a um partido político impõe.

Segundo as entrevistadas, as mulheres são mais disciplinadas, são mais participativas, mais democráticas, pensam e agem com o coração. Uma prefeita defendeu que a principal diferença está na intuição feminina, e assim, consegue perceber as coisas ao seu redor de uma forma mais apurada e diferenciada. Mill (2006) escreveu em 1869 que se uma mulher estiver equiparada com experiência e faculdades gerais, ou seja, que tenha sido capacitada, consegue habitualmente discernir muito melhor do que o homem aquilo que tem perante si, o que ele chamou de 'intuição'.

As mulheres são mais íntegras na política, segundo as entrevistadas. Não se envolvem tanto com corrupção. Na pesquisa de Blay (2001), a imagem de mulher mais trabalhadora e menos corrupta está relacionada com a idealização materna e familiar. Os assuntos sociais são os que interessam às mulheres. Elas são mais sensíveis aos problemas sociais. "Quando entram para a vida político-partidária as mulheres são vistas como mais interessadas em temas como cuidados com crianças, educação, saúde, qualidade de vida. E, de fato, em suas atuações no poder estes temas são os prediletos" (BLAY, 2001).

As entrevistadas acreditam que atuam de forma diferente do homem, que priorizam assuntos relacionados a questões sociais e são mais sensíveis que os homens no tocante a família; para elas, o cuidado com a família, elas replicam na atuação política. Esse cuidado com a família é uma das mais pesadas barreiras enfrentadas pelas mulheres políticas. Percebe-se que ao mesmo tempo o cuidado é a maior barreira e o maior diferencial das mulheres na política.

\subsection{Barreiras e preconceitos que se reproduzem persistentemente}

As mulheres políticas enfrentam obstáculos no exercício do poder que são inerentes de sua condição de mulher? Sim, segundo as entrevistadas, existem preconceitos, e um dos principais obstáculos que enfrentam é o aumento da carga que a política soma a já elevada que precisam carregar em razão do cuidado com a família ${ }^{9}$.

Para as mulheres a 'política não é fácil'. Esse é o entendimento da maioria das mulheres entrevistadas, e a barreira mais forte é a ausência de divisão das tarefas com a família e casa. As mulheres assessoras políticas faziam todo o trabalho de assessoria e ainda cuidavam dos filhos e da casa. Que os homens não têm 'aquele colo para os filhos', que têm dificuldade para levar a médico ou dentista, e então, além do trabalho intenso na política, ainda precisam cumprir as tarefas de mãe e dona de casa.

${ }^{9}$ Na pesquisa de Miriam P. Grossi e Sônia M. Miguel (2001, p. 181), “a temática da maternidade foi uma das que mais mobilizou a fala das participantes". 
Estar na liderança política é conviver com um peso para a mulher. O poder político acaba se tornando um espaço de solidão. Uma prefeita disse que assim que concluir seu tempo de mandato, não abandonará a política, pois gosta muito, mas não quer mais estar na liderança, pois é muito difícil para a mulher. Outro relato de uma vereadora sinaliza essa mesma situação de não poder contar com a parceria do marido, tornando o trabalho na política uma carga por demais pesada. "Parece, pois, que casamento e política são incompatíveis para as mulheres. É como se a mulher tivesse que escolher entre a casa e a política, como relatam muitas mulheres" (BLAY, 2001).

A diferença na rotina da mulher e do homem na política é imensa quando se trata do desafio de conciliar a vida pessoal e profissional, pois o homem conta com uma parceira, e ele sabe que pode contar com essa companheira, que sua vida em casa está andando, mesmo que ele chegue às 23 horas, tem alguma coisa para comer, os filhos estão atendidos, e quando ele sai para o trabalho, a rotina da casa continua. Segundo uma prefeita 'as coisas naturalmente são assim'. Com as mulheres não acontece assim, pois elas estão no trabalho com o pensamento nas atividades que precisam cumprir em casa. Ou seja, elas precisam estar inteiras em casa e inteiras no trabalho. As mulheres não contam com uma primeira-dama.

As regras da política partidária se tornam um fator de crise para muitas mulheres políticas. Algumas relataram que o partido político 'te joga num grupo', te reduz a um grupo de pessoas. O grupo partidário pode se tornar um problema para as mulheres, principalmente em uma cidade pequena, visto ser tudo muito próximo, muito conhecido. Esse foi um dos problemas citados por mulheres que trabalham na política em uma cidade pequena depois de terem atuado como professoras e diretoras de escola.

As participantes informaram que quando estavam na direção da escola tinham contato com muitas pessoas, e quando se tornaram políticas reduziu-se muito seus relacionamentos com pessoas da cidade que antes conviviam. Relataram que seguir as regras da política partidária em uma cidade grande não é tão complicado para a mulher do que quando se está trabalhando em uma cidade menor, onde as pessoas se conhecem, ali nasceram e cresceram e que agora, por causa da política, muitos dos convívios deixaram de acontecer. Que com os homens essa questão partidária quase não existe, eles conseguem muito bem trabalhar com isso, mas que para as mulheres ainda é um fator de crise.

O modo de vestir também é um fator problemático para algumas mulheres na política. A vestimenta pode se tornar um problema, pois, ou precisam modificar seu jeito de vestir, como é o caso de uma vereadora que relatou que depois de se tornar política, passou a usar saia, lenço, salto alto, maquiagem, ou então o desafio passa por manter a forma como que se vestia antes, sem precisar usar o tal do terninho. O desafio colocado em relação às roupas passa pela questão de não perder a essência da mulher, a vaidade feminina, segundo alguns relatos, pois segundo uma política, o estilo de vestir faz parte da identidade da pessoa, e se perder a identidade, a pessoa esquece em o que acredita e as crenças têm ligação com a identidade da pessoa.

Os homens políticos adoram fazer reuniões depois do horário de trabalho. Isso é um problema para mulheres políticas, pois além das reuniões serem longas, ainda alguns homens políticos se reúne em um bar e lá fecham os acordos. Ou seja, os homens se reúnem pós o trabalho e continuam a conversar sobre política, as mulheres não conseguem fazer isso, pois tem a família esperando por elas. Para o participante homem entrevistado, é uma briga desigual, pois o ambiente político é machista, o homem vive a política 24 horas, a mulher não consegue e, em muitos casos, o marido não quer que ela seja política.

Os preconceitos ora destacados nas entrevistas são de diversas ordens, até a profissão de professora pode ser motivo para desencadear atitudes preconceituosas. Professora não sabe lidar com dinheiro, ou 'só 
pode ser coisa de professora', são exemplos de situações relatadas pelas mulheres. A cor da pele também serviu de motivos para algumas atitudes preconceituosas, conforme o relato da primeira prefeita negra do RS, anteriormente citado.

A política ainda se pauta em exclusividade e disponibilidade permanente, condições de vida mais apropriadas para os homens, segundo as entrevistadas. Os homens lideram com mais facilidade porque estão mais centrados na atividade política, as mulheres não conseguem se desligar do dia a dia da casa e família, por isso o exercício da liderança acaba se tornando um fardo pesado para carregar.

\section{Os significados de desenvolvimento local na ótica das mulheres políticas}

O desenvolvimento de um lugar está atrelado às expectativas presentes e futuras de seus cidadãos e a cidadania democrática completa está atrelada a uma participação igualitária de mulheres e homens em espaços de poder de decisão. $\mathrm{O}$ sujeito principal de apreciação neste estudo são as mulheres que exercem função de representatividade política, e é sobre seus olhares sobre o desenvolvimento local ${ }^{10}$ que este estudo se debruça.

Entre os significados sobre desenvolvimento, predominou o trabalho. Ou melhor, a falta de trabalho como fator limitador do desenvolvimento. As mulheres políticas relataram que uma localidade desenvolvida significa as pessoas estarem trabalhando, pois elas irão se sentir úteis e com mais vontade de fazer mais pelo município. As participantes expressaram preocupação nos relatos sobre a falta e / ou reduzida oferta de trabalho em seus municípios.

As prefeitas, vices e vereadoras sempre atuaram na política local, nenhuma delas atuou fora do município. As cidades das participantes são pequenas demograficamente, são consideradas cidades rurais pelas características de produção econômica agropecuária que predomina no local. As participantes relatam preocupação com o fato dos jovens irem estudar em cidades próximas, maiores e com mais oferta de cursos e especializações profissionais, e não retornarem para trabalhar no município onde nasceram. Conforme os relatos, somente voltam à cidade para visitar os parentes que ficaram.

Desenvolvimento local significa interior desenvolvido, segundo uma participante da região do fumo. Como filha de agricultores, defende que as pessoas que moram no interior da cidade precisam contar com uma estrutura de fornecimento de energia, boa estrada para o deslocamento, creche e escolas para os filhos, atendimento de qualidade de saúde e também espaços de lazer. O agricultor precisa dispor de um carro decente para seus deslocamentos até a cidade. Nessa região de fumo, o crescimento econômico da zona urbana depende do interior, então, segundo a prefeita, uma cidade desenvolvida significa um campo desenvolvido, onde as pessoas que lá estão consigam trabalhar com tranquilidade e produtividade.

O desenvolvimento acontece nos bairros, segundo o entendimento de uma vereadora dessa mesma região do fumo. O espaço dos bairros deve ser valorizado pelo poder público local, pois é nesse local que as pessoas vivem, se fortalecem e conseguem ser mais felizes no trabalho. Quando as pessoas vivem em um bairro onde possam transitar com segurança, com locomoção decente para o centro da cidade, com ruas calçadas, limpas e iluminadas, com atendimento de saúde para quando precisar e com creche e escola de qualidade, sua qualidade de vida melhora muito e, consequentemente, será mais produtiva no trabalho. Para a vereadora,

\footnotetext{
${ }^{10}$ Desenvolvimento local tem estreita relação com o comportamento e envolvimento das pessoas que vivem na localidade e privilegia o espaço dos municípios. O desenvolvimento local é um conceito da abordagem bottom-up, que é caracterizada pelo poder de agente das pessoas da localidade no planejamento e tomada de decisões, ou seja, é uma abordagem de desenvolvimento que valoriza a iniciativa, o empreendedorismo das pessoas (BRAUN, 2012).
} 
desenvolvimento somente ocorre quando as pessoas têm trabalho, pois conseguem autossustentarem e, com isso, passam a se sentirem com mais autonomia e felizes.

A pesquisa de Eva Blay (2001) conclui que quando entram para a vida política partidária, as mulheres se envolvem mais com temas como cuidados com crianças, educação, saúde, qualidade de vida. Esses temas são seus prediletos. O acesso a saúde com qualidade também fez parte da maioria dos relatos sobre desenvolvimento. Porém, a ênfase maior a esse tema foi dada por participantes que tem origem na área da saúde, como enfermagem, por exemplo.

Quando as pessoas do município contam com uma estrutura educacional, escola em boas condições, transporte escolar, livros, merenda, professores e alunos interligados, o desenvolvimento ocorre naturalmente, segundo as entrevistadas. Apesar das mulheres políticas destacarem que sem educação não tem desenvolvimento, ainda a questão do trabalho imperou nas conversas das entrevistadas.

A população deve participar das decisões que envolvem o município, essa é a conclusão de uma vereadora que defende o fortalecimento dos Conselhos Municipais como fator de desenvolvimento da localidade. Segundo ela, quando as pessoas opinam nas reuniões dos conselhos, elas se sentem fazendo parte de um sistema onde os representantes políticos são apenas uma pequena parte de um todo. Conselhos atuantes são meios necessários ao desenvolvimento, ou seja, são parte do processo de capacitações que empoderam as pessoas, além de formar ou identificar lideranças entre a comunidade.

Algumas participantes de descendência alemã ${ }^{11}$ defendem que desenvolvimento está relacionado com a aparência da cidade, ou melhor, uma localidade com ruas e calçadas limpas, arborizada, com muitas flores, com espaços públicos bem cuidados. Entendem que quando a cidade está mais bonita, mais bem cuidada, é por que as pessoas daquela localidade também estão cuidando melhor de suas casas e de si mesmas. Percebe-se nas repostas a relação entre casa e trabalho, já referenciado anteriormente.

A ideia de pertencimento a algum lugar pode ser um indício que aquela localidade está 'dando certo'. Segundo uma participante, quando as pessoas da cidade sentem orgulho de dizer de onde são, isso é sinal de desenvolvimento de uma localidade. Para ela, desenvolvimento é isso, as pessoas com orgulho do local onde moram, para tanto, defende que a cultura deve ser incentivada. A prefeita destaca que a cultura coloca as pessoas em movimento; as retiram de casa e as fazem sorrir, colaborando muito para o aumento da auto-estima.

As mulheres políticas compreendem o desenvolvimento local como espaço de cuidado, ou seja, que vai além do crescimento econômico e se torna espaço de chances de vida. Uma cidade desenvolvida é uma cidade bem cuidada. A cidade deve ser cuidada do mesmo jeito que é cuidada uma casa. A relação casa-cidade pode ser considerada como uma característica da feminilidade política? A mulher empoderada politicamente pratica certa extensão dos cuidados da casa ao ambiente público?

Verificou-se que o empoderamento é um instrumento transformador da pessoa e de outras pessoas que estão a sua volta. Que sua efetivação se dá pela conquista dos direitos de cidadania. Que empoderamento está relacionado com os poderes que as pessoas têm para fazer ou deixar de fazer coisas, ou seja, está relacionado com as capacidades conquistadas pela sociedade. Neste estudo, considera-se as expectativas da atuação das mulheres empoderadas politicamente ao desenvolvimento local do município, compreendido como espaço de feminilidade política.

As mulheres compreendem que a promoção da cultura é algo necessário ao desenvolvimento do município, conforme verificou-se nos relatos. Touraine (2011, p. 115) confirma isso em sua obra sobre o mundo das mulheres, pois depois de ouvir suas entrevistas, conclui-se que: "elas dão grande importância aos proble-

\footnotetext{
${ }^{11}$ Mulheres políticas participantes deste estudo que autodeclararam terem descendência alemã.
} 
mas culturais, aqueles que mexem com a vida pessoal, com as relações interpessoais, com as normas morais, com as representações da vida, do amor e da morte".

Para as mulheres, os problemas públicos mais importantes são os que dizem respeito à vida privada. No entanto, segundo Touraine (2011, p. 84), "é falso dizer que as mulheres só se preocupam com a vida privada e os homens com a vida pública". Homens e mulheres têm representações muito diferentes da vida pública; para os homens, a vida pública tem um conteúdo político, para as mulheres, os problemas privados devem ocupar o lugar central da vida pública. Os homens separam a vida pública da privada, as mulheres as unem.

As mulheres desejam que as mudanças sociais ocorram a partir da vida privada antes da vida pública. Touraine (2011, p. 89) se questionou quem são os inimigos das mulheres? Contra quem elas lutam? Concluiu que o inimigo número um delas não é aquele homem dominador, mas a ideia que a vida social e política devem estar separadas da vida privada. "Contrariamente, as mulheres pensam que é necessário partir da vida privada para transformar este espaço público".

A falta de trabalho, o precário atendimento às pessoas que precisam de atendimento de saúde, a busca pela estruturação das escolas como ambiente de aprendizado com qualidade, a insegurança, foram os destaques nos relatos das mulheres políticas a respeito do que seria uma localidade desenvolvida. Mas, principalmente, elas descreveram um município desenvolvido como aquele onde as ruas e calçadas, espaços públicos, estão limpas, sem lixo espalhado, iluminada, arborizada, com flores, onde a cultura seja promovida e estimulada, e onde as pessoas tenham orgulho de dizer que pertencem aquele lugar.

O desenvolvimento passa a ser uma questão de cuidado com a aparência da cidade, tanto na área rural como urbana. Áreas ditas sociais, saúde, educação, meio ambiente, têm mais espaços com as mulheres na política. Nessa ótica, vê-se a união da esfera familiar e a laboral.

A leitura dos relatos das políticas é a que o desenvolvimento passa pelo cuidado com o ambiente onde elas estão desempenhando a função na política representativa, sem excluir a esfera privada. O desenvolvimento ocorre num espaço de liberdade, de promoção de chances de vida, de confiança e expectativas elevadas. E esse espaço pode ser concretizado em um ambiente arborizado e com muitas flores.

\section{Conclusões}

"Se os mundos feminino e masculino fossem completamente distintos, simples seria a tarefa do cientista. Dada, porém, a natureza complementar das relações entre homens e mulheres, cabe buscar-se, nas oposições estruturais de certa formação social, as determinações essenciais do sistema de produção de bens e serviços capazes de explicar, a um só tempo, os papéis masculinos, os papéis femininos e a natureza complementar de ambos na família e na sociedade”. Heleieth Saffioti - Professora (SAFFIOTI, 2013, p. $505)$.

Neste estudo, tratou-se sobre mulheres, política e desenvolvimento. Compreendeu-se que, quando uma mulher exerce função de representatividade política e passa a fazer parte da elaboração de políticas de desenvolvimento local, as experiências vivenciadas no lar a acompanham em suas ações e então o desenvolvimento passa a ter outros significados além do crescimento econômico. O escopo de análise é a mulher sujeito do desenvolvimento na esfera de decisão política representativa e o desenvolvimento local como sinônimo de melhoria das condições de vida das pessoas no meio onde vivem.

A participação feminina massiva em espaços de poder e decisão ainda representa uma utopia para mulheres brasileiras. No Rio Grande do Sul, nas eleições de 2012, nem 10\% das prefeituras são ocupadas por mulheres. Resultados que não diferem muito do restante dos estados brasileiros, em que as mulheres estão sub 
-representadas politicamente. Como verificou-se, a cultura patriarcal machista de homens e mulheres coloca a mulher no ambiente privado e o homem no ambiente público, sendo que na política o domínio é dos homens com argumento de que mulheres não sabem ou não gostam de política.

Perante tal situação da realidade, decidiu-se investigar o tema a fim de compreender como está sendo construído o espaço de poder político por meio da trajetória de mulheres percorrida na política, as especificidades de seu trabalho e suas compreensões sobre desenvolvimento. As principais questões sobre a participação feminina na política ao que se propôs neste estudo são as seguintes:

Primeiramente, verificou-se que a trajetória de empoderamento político de mulheres é compreendida de três formas: pela profissão desempenhada anteriormente, principalmente na área de educação; pela participação em movimentos sociais; e como resultado de uma decisão na esfera privada, onde a mulher ao se candidatar a cargo eletivo está cumprindo uma decisão de familiares. Destaca-se que essas três formas de integração à esfera política não são excludentes em si, ao contrário, podem ser complementares.

A mulher política compreende o desenvolvimento local de uma forma humanizadora e solidária aos moldes do que vive na família/casa/esfera privada, onde os assuntos relacionados com a vida das pessoas são os mais importantes.

Quando estavam do lado de fora da política, viam como um lugar apavorante, sem condições de atuar, que não abria espaço para elas, no entanto, quando precisaram entrar, por diversos motivos, ficaram surpresas com a própria capacidade de atuação. Já pertencentes a esse mundo, perceberam que havia necessidade de trabalhar muito, dedicar-se muito, pois, por sua condição de mulher, precisam provar a cada dia sua capacidade, tanto para os colegas de trabalho, como para a sociedade. Perceberam que a esfera política é muito diferente de quando atuavam como diretoras de escola, onde mantinham relação de confiança com a maior parte das pessoas da comunidade, sem distinção partidária. É preciso conhecer as regras do jogo político.

As mulheres reconhecem que a política ainda é um ambiente dominado por homens, no entanto, também reconhecem que têm capacidade para jogar, não com as mesmas regras que os homens utilizam, mas com regras que tem conhecimento e experiência: as regras da esfera privada. Porém, neste estudo verificou-se que a formação de uma massa crítica que seja suficientemente grande para provocar alteração qualitativa na esfera de poder político, ainda não é a realidade da representatividade feminina no Brasil.

Por último, percebeu-se que as mulheres que atuam na política não costumam separar os cuidados que preservam em casa com seus interesses na esfera política. Existe uma linha tênue que separa a esfera privada e pública, a qual pode se tornar um verdadeiro sacrifício na tentativa de separação, pois compreendem que devem utilizar as experiências da vida privada para transformar a esfera política. As mulheres atuam diferente dos homens na esfera política.

Por fim, compreende-se que, quando mais mulheres ingressarem na política representativa pela trajetória da participação em movimentos sociais, a qualidade da participação política tenderá a se elevar e refletirá em um processo de desenvolvimento local fundamentado na responsabilidade solidária da sociedade. Afinal, para as mulheres políticas, desenvolvimento tem relação com sentir-se bem em um local e afirmar esse entendimento para outras pessoas.

\section{Referências}

ABREU, Maria Aparecida Azevedo. Cotas para mulheres no legislativo e seus fundamentos republicanos. Texto para discussão nº 1645. Brasília: Instituto de Pesquisa Econômica Aplicada - IPEA, agosto de 2011. 
ALVES, Branca Moreira; PITANGUY, Jacqueline. O que é feminismo. São Paulo: Brasiliense, 2007.

ARAÚJO, Clara. As mulheres e o Poder Político - Desafios para a democracia nas próximas décadas. In: BARSTED, Leila Linhares; PITANGUY, Jaqueline. (Org.). O Progresso das Mulheres no Brasil 2003-2010. Rio de Janeiro: CEPIA; Brasília: ONU Mulheres, 2011. p. 92-136.

ARENDT, Hannah. O que é política? Tradução de Reinaldo Guarany, 2. ed., Rio de Janeiro: Bertrand Brasil, 1999.

AVELAR, Lúcia. Mulheres na elite política brasileira. São Paulo: Fundação Konrad Adenauer, Editora da UNESP, 2001.

BANDEIRA, Lourdes; MELO, Hildete Pereira de. Memórias das lutas Feministas no Brasil. Secretaria de Políticas para as Mulheres. Presidência da República. Brasília: SPM, 2010.

BAQUERO, Rute V. Empoderamento: questões conceituais e metodológicas. REDES, Santa Cruz do Sul, v. 11, n. 2, p. 77-93, mai./ago. 2006.

BAQUERO, Rute V. Empoderamento: Instrumento de Emancipação Social? - Uma Discussão Conceitual. Revista Debates, Porto Alegre, v. 6, n. 1, p. 173-187, jan./abr. 2012.

BARCELLOS, Olinda; COMIM, Flávio V. Compreensões de pobreza: os distintos sentidos encontrados na Literatura Brasileira. In: ENCONTRO NACIONA DE ECONOMIA - ANPEC, 40., 2013, Porto Alegre. Anais... Porto Alegre, RS: ANPEC, 2012. p.1-20. Disponível em: $<$ http://www.pucrs.br/eventos/encontroeconomia/download/mesas/CompreensoesDePobreza.pdf>. Acesso em: 13 abr 2013.

BARSTED, Leila Linhares. Os avanços no reconhecimento dos direitos das mulheres. Autonomia econômica e empoderamento da mulher: textos acadêmicos. Brasília: Fundação Alexandre de Gusmão, 2011. $304 \mathrm{P}$. BEAUVOIR, Simone. O segundo sexo. Tradução de Sérgio Milliet. 2.ed. Rio de Janeiro: Nova Fronteira, 2009. 2v.

BLAY, Eva Alterman. Um caminho ainda em construção: a igualdade de oportunidades para as mulheres. Política e Participação. Revista USP, São Paulo, n. 49, p. 82-97, mar./mai. 2001.

BLAY, Eva Alterman. As Prefeitas: A participação Política da Mulher no Brasil. Rio de Janeiro: Avenir Editora Limitada, 1979.

BRASIL. Constituição da República Federativa do Brasil de 1988. 1988. Disponível em: <http://www.planalto.gov.br/ccivil_03/constituicao/constituicaocompilado.htm>. Acesso em: 05 nov. 2013.

BRASIL. MAIS MULHERES NA POLÍTICA (MMP). Livreto Mais Mulheres na Política: Mulher, Tome Partido!. 2012. Brasília: Procuradoria da Mulher, Senado Federal, Bancada Feminina da Câmara dos Deputados, Procuradoria Especial da Mulher e Câmara dos Deputados. Disponível em: <http://www12.senado.leg. br/senado/procuradoria/publicacao/livreto-mais-mulheres-na-politica $>$. Acesso em: 02 nov. 2014.

BRASIL. Presidência da República. Secretaria de Políticas para as Mulheres. Plano Nacional de Políticas para as Mulheres. Brasília: Secretaria de Políticas para as Mulheres, 2013.

CÂMARA MUNICIPAL DE MUQUi/ES. Biografia da Nenen Paiva. s/d. Disponível em: <http://www.camaramuqui.es.gov.br/museu_virtual.asp?id=139>. Acesso em: 15 dez. 2014.

CANO, Ignácio. Nas trincheiras do método: o ensino da metodologia das Ciências Sociais no Brasil. Sociologias, Porto alegre, v. 14, n. 31, p. 94-119, set./dez. 2012.

CARR, Marilyn. EI empoderamiento econômico de las mujeres: clave del desarrolo. Nueva York: UNIFEM - Fundo de Desarollo de Las Naciones Unidas para la Mujer, 2000.

CORAZZA, Gentil (Org.). Métodos da Ciência Econômica. Porto Alegre: Editora da UFRGS, 2003.

COSTA, Ana Alice Alcântara. Donas do Poder - Mulher e política na Bahia. Salvador: NEIM / UFBA - As- 
sembléia Legislativa da Bahia, 1998.

COSTA, Ana Alice Alcântara. Gênero, Poder e Empoderamento das mulheres. 2012. Disponível em: $<$ https://pactoglobalcreapr.files.wordpress.com/2012/02/5-empoderamento-ana-alice.pdf $>$. Acesso em: $06 / 11 / 2014$.

COSTA, Ana Alice Alcântara. O movimento feminista no Brasil: dinâmicas de uma intervenção política. Revista Gênero, Rio de Janeiro, v. 5, n. 2, p. 1-20, jan. 2005.

DAHLERUP, Drude. De uma pequeña a uma gran minoria: uma teoría de la "masa crítica" aplicada al caso de las mujeres em la política escandinava. Mujeres al Timón en la Función Pública, 1986. (Manual de Liderazgo Social). Disponível em: <http://www.redfeminista.org/nueva/uploads/masa\%20critica.pdf $>$. Acesso em: 5 jul. 2014.

DAHRENDORF, Ralf. O conflito social moderno: um ensaio sobre a política da liberdade. Tradução de Renato Aguiar e Marco Antonio Esteves da Rocha. Rio de Janeiro: Jorge Zahar Editor - Editora da Universidade de São Paulo, 1992.

DEERE, Carmem Diana e LEÓN, Magdalena. O empoderamento da mulher: Direitos à terra e direitos de propriedade na América Latina. Tradução: Letícia Vasconcellos Abreu, Paula Azambuja Rossato Antinolfi e Sônia Terezinha Gehring. Porto Alegre: Editora da UFRGS, 2002.

DIAS JUNIOR, Antonio C. Classe, Política e Conflito Social no Capitalismo: A Contribuição de Ralf Dahrendorf. Mediações, Londrina, v. 15, n. 2, p. 202-218, jul./dez. 2010.

DIAS JUNIOR. Ralf Dahrendorf (1929-2009): Réquiem para um sociólogo liberal. Tempo Social, São Paulo, v. 23, n. 2, p. 321-334, nov. 2011.

DUARTE, Rosália. Pesquisa Qualitativa: reflexões sobre o trabalho de campo. Cadernos de Pesquisa, Santa Cruz do Sul, n. 115, p. 139-154, mar. 2002.

FEE - Fundação de Economia e Estatística. Perfil socioeconômico - Municípios. 2014. Disponível em: $<$ http://www.fee.rs.gov.br/perfil-socioeconomico/municipios/>. Acesso em: 23 set. 2014.

GIL, Antonio Carlos. Métodos e técnicas de pesquisa social. 4. ed., São Paulo: Atlas, 1995.

GROSSI, Miriam Pillar; MIGUEL, Sônia Malheiros. Transformando a diferença: as mulheres na política. Revista Estudos Feministas, Santa Catarina, v. 9, p. 167-195, jul. 2001.

INSTITUTO BRASILEIRO DE GEOGRAFIA E ESTATÍSTICA - IBGE. IBGE Cidades Rio Grande do Sul. 2015. Disponível em: <http://www.cidades.ibge.gov.br/xtras/uf.php?coduf=43\&search=rio-grande-dosul\&lang>. Acesso em: 25 fev. 2015.

LAKATOS, Eva Maria; MARCONI, Marina de Andrade. Metodologia científica. 7. ed., 2. reimpressão, São Paulo: Atlas, 2010.

MIGUEL, Luiz Felipe. Mulheres e espaços de poder no Brasil. Autonomia econômica e empoderamento da mulher: textos acadêmicos. Brasília: Fundação Alexandre de Gusmão, 2011. p. 139-155.

MILL, John Stuart. A Sujeição das Mulheres. Tradução de Benedita Bettencourt. Coimbra: Edições Almedina S. A. Julho, 2006.

PRÁ, Jussara Reis. Mulheres permanecem à margem da arena política. Entrevista concedida ao Jornal Beira do Rio, da Universidade Federal do Pará, edição $n^{\circ}$ 66, ano 2008. Disponível em: < http://www.ufpa. br/beiradorio/novo/index.php/2008/12-edicao-66/125--mulheres-permanecem-a-margem-da-arena-politica> . Acesso em: 23 nov. 2014.

PRÁ, Jussara Reis. O Custo Político das Desigualdades de Gênero e a Teoria do Capital Social. Educação Unisinos. São Leopoldo, Unisinos, v. 9, n. 2, p. 99-115, mai./ago. 2005, 
PRÁ, Jussara Reis. Representação política da mulher no Brasil, 1982-1990: a articulação de gênero no sul do país e a questão institucional. 1992. Tese (Doutorado em Ciência Política). Universidade de São Paulo, Programa de Pós-Graduação em Ciência Política, São Paulo, 1992.

PRÁ, Jussara Reis; EPPING, Léa. Cidadania e feminismo no reconhecimento dos direitos humanos das mulheres. Estudos Feministas, Florianópolis, v. 20, n. 01, p. 33-51, jan./abr. 2012.

RIDENTI, Marcelo Siqueira. As mulheres na política brasileira: os anos de chumbo. Tempo Social - Revista Social USP, São Paulo, v. 1, n. 1, p. 113-128, jul. 1990.

SAFFIOTI, Heleieth I. B., A mulher na sociedade de classes: Mitos e realidades. São Paulo: Editora Expressão Popular, $3^{\mathrm{a}}$ edição, 2013.

SEN, Amartya Kumar Desigualdade reexaminada. 2. ed., Rio de Janeiro: Editora Record, 2008.

Desenvolvimento como liberdade. São Paulo: Companhia das Letras, 2010.

TILLY, Louise A. Gênero, história das mulheres e história social. Cadernos Pagu, Campinas, v. 3, p. 29-62, jul. 1994.

TOURAINE, Alain. Lo que llamamos 'política' es hoy uma realidad muy degradada. Entrevista concedida à Revista da Cultura. Por Fábio Gambaro. 2014. Disponível em: <http://www.revistaenie.clarin.com/ideas/ Alain-Touraine-llamamos-politica-hoy-realidad-degradada_0_1062493967.html>. Acesso em: 27 dez. 2014.

TOURAINE, Alain. O mundo das mulheres. Tradução de Francisco Moras. 3. ed., Petrópolis, RJ: Vozes, 2011.

TOURAINE, Alain. Crítica da Modernidade. Tradução de Elia Ferreira Edel. Petrópolis, RJ: Vozes, 1994.

TRE/RN - Tribunal Regional Eleitoral do Rio Grande do Norte. Os 80 anos do voto de saias. Institucional/ Centro de Memória. 08 de maio de 2012. Disponível em: <http://www.tre-rn.jus.br/institucional/centro-dememoria/os-80-anos-do-voto-de-saias-no-brasil-tre-rn>. Acesso em: 12 set. 2014.

TRIBUNAL SUPERIOR ELEITORAL - TSE. Eleições - Resultados. 2014. Disponível em: <http://www. tre-rs.jus.br/index.php?nodo=278>. Acesso em: 13 out. 2014.

\section{APÊNDICE A - ROTEIRO DA ENTREVISTA COM MULHERES ELEITAS}

Data da entrevista:

\section{Identificação}

Nome:

Estado Civil:

Tem filhos? Quantos?

Trajetória da família: origem, etnia, números de familiares, situação social, ruralidade.

II. Estudos e profissão: base de estudos, a profissão

III. Trajetória política: caminho percorrido, organização de grupo (Sindicatos, Partido político, Cooperativas, Associações comunitárias, conselhos municipais, grupos religiosos), incentivos (familiares, amigos, agentes políticos, conhecidos, outros). 
IV. Atuação na política: estilo de fazer política, valores (afetividade, solidariedade, cuidado, sentimento materno, conciliação, especificidades do ambiente familiar), consciência feminista (atuação feminista na política versus mulher na política), incentivos (ajuda no trabalho), desafios (problemas).

V. Desenvolvimento local: significado, temas relevantes (temas importantes a serem politizados e defendidos na arena política), o papel da mulher política para o desenvolvimento.

VI. Ações para o desenvolvimento: práticas, projetos, mulheres rurais

VII. Mulher na política e igualdade de gênero: preconceito, incentivos (para outras mulheres ainda não empoderadas), representatividade feminina, fatores de sucesso, consciência feminista, condições de empoderamento político.

VIII. Estado de confiança: autonomia (auto reconhecimento, reconhecimento pelos outros), exercício da política (o que a presença da mulher pode acrescentar à prática política), expectativas (condição da mulher entrevistada na política):

( ) Baixo (entre zero até 3)

( ) Regular (mais de 3 até 5)

( ) Bom (mais de 5 até 7 )

( ) Muito bom (mais de 7 até 9)

( ) Ótimo (acima de 9).

IX. Projetos futuros (sonhos): na vida familiar, na vida profissional, na política. 